\title{
FUNCTIONING DISCOURSE MARKERS TO CONSTRUCT A SOCIAL SITUATION IN SPEECH
}

\section{Gusti Agung Sri Rwa Jayantini, I Wayan Juniartha, I Kadek Arya Aditana, Ronald Umbas, Ni Komang Arie Suwastini}

\author{
agung_srijayantini@unmas.ac.id \\ Universitas Mahasaraswati Denpasar \\ Denpasar, Bali, Indonesia
}

\begin{abstract}
This study relates the discussion of discourse markers to their functions from a social context. It aims to identify discourse markers and analyze their function to construct a social situation in Steve Jobs' speech delivered at Stanford Commencement Address. To analyze the data in this study, the researchers used a qualitative descriptive method. This study showed that the dominant discourse markers used were connective, followed by cause \& result, temporal adverb, and marker of response, respectively, in which the last marker was the least used. Furthermore, all discourse markers functioned to gain coherent message delivery in the speech by considering the "setting and scene," "participants," "ends," "act sequence," "key," "instrumentalities," "norms of interaction," and "genre," all of which were shortened in the acronym of "speaking." Finally, based on its social situation, the present study is expected to broaden the understanding of discourse markers in a particular text.
\end{abstract}

Keywords: discourse markers; speech; social situation

\section{INTRODUCTION}

As a form of oral communication, a speech requires the speaker to express their ideas clearly. To interact with the target audience, the speech must be supported by several fascinating facts, strong arguments, and rhetorical expressions. Powerful speeches make people enjoy the skill with which the words are crafted, the way the speakers deliver them to inspire the audience (Collins, 2012; Agbontaen, 2019). By preparing a wellorganized talk, the speaker intends to attract the audience's attention and concentrate on discussed topics.

The art of delivering a speech can be seen from the content presentation that relates to how eye-opening the idea is constructed and the performance involving well-controlled gestures. Concerning the content, speech is usually structured as a spoken form of communication that allows the speaker to prepare the talk in a written form before its presentation. It must have crystal- clear details and be of the most interest to the audience (Agbontaen, 2019; Stewart \& Fulop, 2019). Meanwhile, concerning the performance, the speaker has to convey the speech with proper articulation, intonation, tone, and voice considered some technical features. Speaker is considered successful when they can share a good topic by paying careful attention to comprehensive language and cohesiveness in the speech. In making the speech more understandable, discourse markers (henceforth DMs) are needed as the connectors between the ideas or topics. The cohesiveness in a speech is worth analyzing as a reference to develop the skill in delivering a speech (Abdullah, 2018). More importantly, in the speeches of public figures, DMs are used to present organized elaboration to establish a connection with their audience (BanguisBantawig, 2019). DMs are related to the idea of connectivity that encourages researchers to pinpoint the markers across contexts, languages, and periods (Maschler \& Schiffrin, 
2015). DMs are related to the lexicons used to indicate the structure and particular denotations in the context of scientific studies that play their specific functions (Rezanova \& Kogut, 2015).

Since DMs have their specific function or an addition to the existing basic meaning seen from the semantic and pragmatic viewpoint, Fraser (2010) preferred to use the term Pragmatics Markers (PMs) to reach a broader scope of discussion reflecting more examples used to negotiate meaning in a social context. They are lexical expressions owing to the features of free morphemes, and propositioninitial functioned. DMs are parts of PMs that are treated as three types of markers. First, Contrastive Markers (CDMs) mark direct or indirect contrastive ideas between two statements, for example, but, although, in contrast. Another category is Elaborative Markers (EDMs) that show the connection of information in the second statement toward the information found in the first statement as represented by and, above all, after all, also, etc. Meanwhile, Inferential Markers (IDMs) signal that the first statement involves the second statement in a causal-effect relation that is represented by so, as a result, because, consequently, etc.

The frequent predominant DMs used in speech are connective (Marbun, 2017; Banguis-Bantawig, 2019). The marker of the connective is used as a continuation unit that connects the speaker's statements and serves a more general point (Marbun, 2017). DMs functioned as connectives are meant to show the additional information. At the same time, DM substitution is found by Banguis-Bantawig (2019) to be the most predominantly used by Asian presidents in their speeches. With prominent use of DM, particularly substitution (personal pronouns), the presidents establish a social connection with the audience through his speeches. The "what and how" of DMs found in speeches are utilized to build the social connection, i.e., between the speaker and the audience.

This consideration has not been much explored in Marbun (2017) and BanguisBantawig (2019). Referring to the two previous studies, this research aims at investigating types of DMs and how they function to construct a social situation in the speech with the help of sociolinguistic theory.
The theory is used to reveal the features of language for social interaction, in this case, the statements in the speech seen from the 'speaking' aspects. It makes the design of this study differs from the previous studies. The present research attempts to offer a new model of discussion on the use of DMs in a speech related to its social context. The analyzed speech in the study was Steve Jobs' Standford Commencement Address in 2005. All DMs utilized in his speech function to connect Steve Jobs' three stories, i.e., connecting the dots, love, and loss, and death that was prominently told the audience about the significance of particular events to the other events happening in one's life. Jobs' stories in this speech were full of encouragement for everyone to chase their life goals and see the changes in the ups and downs, struggles, failure, and even to face death.

\section{Discourse Markers}

DMs occur throughout the discourse. In daily social interaction, the use of DMs is various. The existence of DMs in different levels of spoken communication is irrefutable (Belicová, 2011). In discussion, there are several kinds of DMs, such as markers of information management like "oh," marker of responses "well," the connectives like "and," "but," "or," markers of cause and results are represented by "so" and "because," markers of a temporal adverb like "now" and "then," markers of information and participation include "you know" or "I mean" (Schiffrin (1987).

DMs are linguistic devices utilized to relate the pieces of language or expression. The application of DMs in different texts has been long investigated with their specific purposes. DMs are applied in spoken means like speech and talk shows (Marbun, 2017; Uicheng \& Crabtree, 2018; Banguis-Bantawig, 2019; Kusumayati, 2020). DMs utilized in the speeches involve connecting ideas, presenting cause and result, showing time sequence, managing information, and ideational structure involving continuation or turn in delivering the involved parties' opinions. Meanwhile, in written text, the effective use of DMs is to realize effective academic writing (Sharndama \& Yakubu, 2013) and investigate the possibilities of comparing the use of 
cohesive devices as discussed by Yuhas (2013). More interestingly, DMs may improve the quality of writing and promote text comprehension. It is done by mapping how to do coherent writing by understanding the insignificant use of DMs, the overuse of DMs, the advanced use of DMs (Al-khazraji, 2019), and gender differences in using DMs (Yeganeh \& Ghoreyshi, 2015).

\section{Del Hymes' Speaking Model}

Hymes' 'speaking model' as discussed by Ray \& Biswas (2011), covers the "setting and scene," "participants," "ends," "act sequence," "key," "instrumentalities," "norm," and "genre" in a speech event. "Setting and scene" refer to time, place, and its environment. "Participants" are the involved parties in the speech event, including the speaker and hearer. "Ends" are related to the objectives of the speech. "Act sequence" refers to the order of events. "Key" is the spirit of interaction. "Instrumentalities" are the channel of communication, like written or spoken. "Norms of interaction" include the attitudes attached to the speech event. "Genre" covers the type of utterance like a lecture, speech, prayers, etc. All of these features are considered relevant to investigate all aspects included in the social situation of the speech. The analysis of the social situation is conducted to strengthen the discussion on DMs. Therefore, the 'speaking model' is expected to contribute to the analysis elaboration of choosing DMs in specific contexts.

The 'speaking model' reflected the idea of Hymes (1974), who discussed the principles of social contexts in communicative events. The social contexts include the participants (speaker-hearer), modes of communication (spoken or written), the codes shared by the involved participants (paralinguistic and the types of communication events like communicative, interpretative, and interactive). Besides, communication settings must also be part of the ambiance considered important as social aspects of communication. Other aspects included as social contexts of communication are the genres of messages, the contents, and events. These items can be used as the standards to analyze one type of spoken communication like a family story (Umezinwa,
2019), meetings in an academic situation (Ray \& Biswas, 2011), as well as comedy television stories (Zand-vakili et al., 2012). Meanwhile, this study tries to connect the analysis of DMs and the social context of a speech to deliver ideas and thoughts.

\section{METHODOLOGY}

This study employed a qualitative descriptive method through observation and content analysis. The observation applied included a note-taking technique to collect the data. The researcher downloaded the data source, Steve Jobs' Stanford Commencement 2005 speech video from https://www.youtube.com/watch?v=UF8uR6 Z6KLc. The speech was thoroughly observed by watching the whole video with its subtitle. Meanwhile, content analysis was undertaken by carefully reading the whole speech script that was available in https://news.stanford.edu/2005/06/14/jobs061505/. The performance of Steve Jobs at Stanford University is captured in figure 1.

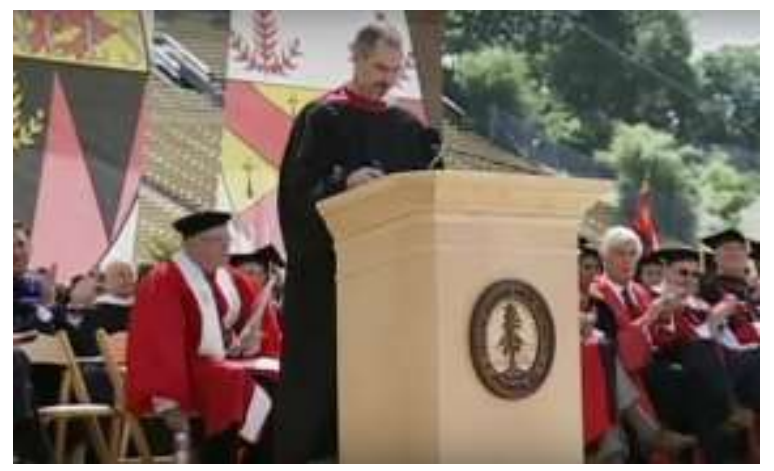

Figure 1. Steve Jobs' Stanford Commencement Speech in 2005

When identifying discourse markers, a note-taking technique was adopted to record the relevant data suited to each DM category. In the tabulation process, the number of markers was carefully counted based on Schiffrin's classification, namely markers of information management, markers of responses, markers of connectives, markers of cause and results, markers of temporal adverb, markers of information, and participation. Before data analysis, checking the validity of the collected data was made by paying careful attention to the data. Reduction to several data was also made when the inappropriate classification was previously made. In this step, the irrelevant data were eliminated. 
The methodological framework is shown in figure 2 . The analysis pattern covers the identification of a speech event, the 2005 graduation at Stanford University. Steve Jobs' speech was considered a motivational speech. The analysis of discourse markers was then combined with the social situation represented by all eight factors of Hymes' 'speaking model .'Two steps were realized in line with the categories of DMs and Hymes' speaking model to make a comprehensive analysis. First, the classified data were analyzed following the classification of DMs. Each classification was analyzed by referring to its examples, and the interpretation was based on Schiffrin (1987). Second, all aspects of Hymes 'speaking model' as further discussed by Ray \& Biswas (2011) concerning the analysis of spoken discourse to show the actual speech event was also used.

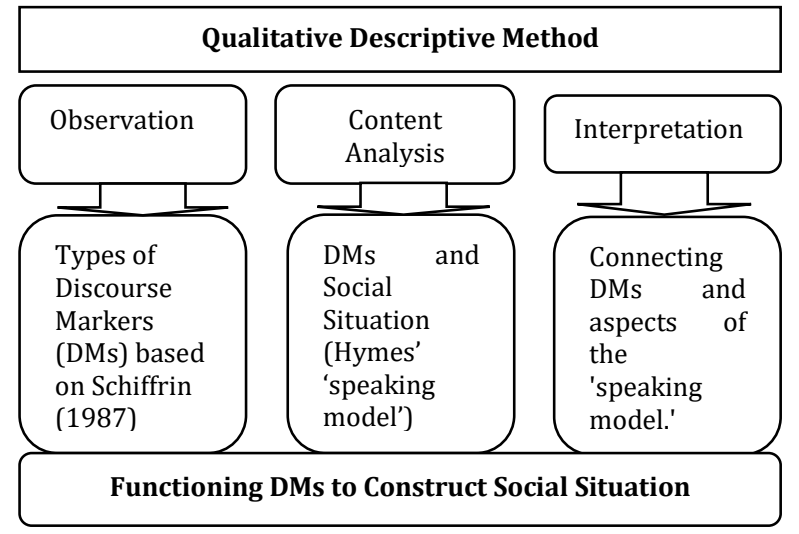

Figure 2. Methodology Framework

\section{RESULT AND DISCUSSION}

This study is aimed at examining the use of DMs and their function to establish social interaction in the exciting presentation. Del Hymes' 'speaking model' was used to explain the comprehensiveness of this theory that included the features of a social situation when speakers and hearers were involved in a particular speech event. Hymes, as cited in Johnstone \& Marcellino (2010), offers the wide opening window to the study of language and society, i.e., sociolinguistics. Formal presentations of the results (table 1 and table 2) show the number of DMs used in the speech and interpret all aspects in 'speaking' as found in Steve Jobs' Standford commencement address. The presentation in table 2, specifically, leads to an elaboration that shows more visible results on how this study is different from the previous studies to map the relationship between DMs and the social situation in the speech by utilizing Del Hymes' speaking model.

The analysis of this study resulted in two significant findings. First, of 109 data, there were 82 markers of connective $(75,2 \%)$, 16 markers of cause \& result $(14,7 \%), 10$ markers of temporal adverb $(9,2 \%)$, and only 1 marker of response $(0,9 \%)$. All DMs were predominantly used to present the social aspects in the speech, particularly "ends," "act sequences," and "key" because these three aspects are strongly related to the content of the speech reflecting the significance of connectivity, causal relations, temporal relations, as well as reactions. Second, the identification of the 'speaking model' is presented in table 2 as the basis of discussion on each type of DMs found in the speech.

Table 1. DMs found in Steve Jobs' Stanford Commencement Address.

\begin{tabular}{|c|c|c|c|}
\hline $\begin{array}{l}\text { Discourse } \\
\text { Markers }\end{array}$ & Type & $\begin{array}{l}\text { Occurrenc } \\
\mathrm{e}\end{array}$ & Percentage \\
\hline \multirow{3}{*}{$\begin{array}{l}\text { Markers of } \\
\text { Connective }\end{array}$} & And & 64 & 58,7 \\
\hline & But & 14 & 12,8 \\
\hline & Or & 4 & 3,7 \\
\hline \multirow{2}{*}{$\begin{array}{l}\text { Markers of } \\
\text { Cause and } \\
\text { Result }\end{array}$} & Because & 4 & 3,7 \\
\hline & So & 12 & 11 \\
\hline \multirow{3}{*}{$\begin{array}{l}\text { Markers of } \\
\text { Response } \\
\text { Markers of } \\
\text { Temporal } \\
\text { Adverb }\end{array}$} & Well & 1 & 0,9 \\
\hline & Now & 6 & 5,5 \\
\hline & Then & $\begin{array}{c}4 \\
109\end{array}$ & $\begin{array}{c}3,7 \\
100\end{array}$ \\
\hline
\end{tabular}

Source: Schriffrin's Categories of DMs

Table 1 presents the marker of connective "and" as the most dominant DMs in Steve Jobs' speech. The marker "and" take the highest percentage because it plays a significant role in linking the statements used to support the inspiring stories that Steve Jobs conveys. The response "well" marker is found as the most infrequently used marker in the speech, which is only $1 \%$. It is because the speech is set on a formal occasion. The script of the speech has also been well written before its delivery. Thus, the marker of response is not used as part of repairs. "Well" in the speech marks the effort to develop the speech's content to strengthen Jobs' statement. 
Table 2. Social aspects are found in Steve Jobs' Stanford Commencement Address.

\begin{tabular}{|c|c|}
\hline 'Speaking Model' & Detailed Evidence \\
\hline Setting and Scene & $\begin{array}{l}\text { The event took place in Stanford } \\
\text { Stadium of Stanford University, } \\
\text { the United States of America, on } \\
12 \text { June } 2005 \text {. Steve Job was } \\
\text { chosen to deliver his } \\
\text { motivational speech at a formal } \\
\text { event: the graduation ceremony. }\end{array}$ \\
\hline Participants & $\begin{array}{l}\text { The participants were Steve Jobs, } \\
\text { stakeholders or committee of the } \\
\text { event, students of Stanford as } \\
\text { well as family and friends, faculty } \\
\text { members, and lecturers of } \\
\text { Standford University, }\end{array}$ \\
\hline Ends & $\begin{array}{l}\text { The purpose or goal was to } \\
\text { motivate the alumni to face the } \\
\text { real working world. }\end{array}$ \\
\hline Act $S$ & $\begin{array}{l}\text { Steve Jobs delivered his own } \\
\text { story about his past from his } \\
\text { birth to his struggles in reaching } \\
\text { what he wanted in life. }\end{array}$ \\
\hline Key & $\begin{array}{l}\text { Steve Jobs delivered his speech } \\
\text { about his past. The arrangement } \\
\text { of the story was made from the } \\
\text { time Steve Jobs was born to the } \\
\text { days he could reach his success. } \\
\text { It was well presented, just like a } \\
\text { storytelling presentation. He put } \\
\text { the values and messages within } \\
\text { the story to motivate and inspire } \\
\text { the audience. }\end{array}$ \\
\hline Instr & $\begin{array}{l}\text { It is a spoken form of } \\
\text { communication }\end{array}$ \\
\hline $\begin{array}{l}\text { Norms } \\
\text { Interaction }\end{array}$ & $\begin{array}{l}\text { The speaker cannot be } \\
\text { interrupted by the audience } \\
\text { because it is a kind of interactive } \\
\text { presentation. }\end{array}$ \\
\hline Genre & $\begin{array}{l}\text { The genre is a motivational } \\
\text { speech }\end{array}$ \\
\hline
\end{tabular}

Source: Del Hymes' speaking model (as developed by Ray \& Biswas (2011).

Table 2 shows the social situations in Steve Jobs' speech. Each aspect of the 'speaking model' is briefly presented in the table. The speech is delivered on the formal occasion of Stanford University graduation. The formality of the event can be identified from the involved participants. They are the committee of the event, the alumni with their family and friends, the top leaders and lecturers of Stanford University. The dominant aspects of the 'speaking model' that are related to the content of the speech are "ends," "act sequences," and "key ."These three aspects are connected to the sequence of stories in the speech since they include the significance of connectivity, causal relations, temporal relations, and reactions. The detailed evidence in table 2 is used to support the analysis of DMs found in the speech. Meanwhile, the relation between the utilization of DMs and all aspects of speaking consists of setting and scene, participants, ends, act sequence, key, instrumentalities, norm, and genre, as shown in figure 2 .

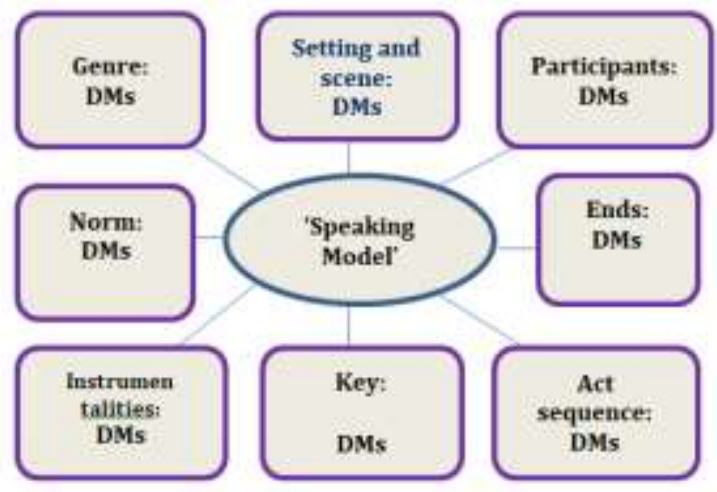

Figure 2. DMs in and Steve Jobs' speech and its social situation (modified from Hymes, 1974)

Figure 2 reflects the relationship between all aspects of the 'speaking model' with the DMs used in the speech to reach the function of making a speech as a medium of social interaction. When investigating DMs and their social context in speech delivery, the interpretation its covers is on how DMs are related to "setting and scene," "participants," "ends," "act sequence," "key," "instrumentalities," "norm" and "genre." All of the aspects demonstrate the social situation reflected in a speech as a means of communication. A speech is written to be read aloud by the speaker to achieve the speech goal, which is the "ends" aspect of 'speaking.' To be inspired by an inspiring experience and a story by the speaker, the participants must be connected by a good speech that is delivered using the DMs relevant with the context. Coherence in Steve Jobs' speech helps the audience ("participants") understand the meaning implied behind all statements linked by the DMs. Under the occasion and the place where Jobs delivered the speech ("setting and scene"), he must utilize all types of DMs to share the values in his speech ("key" and "genre"). The three stories of Jobs' life are written in his speech text ("instrumentalities") expressed in sentences using DMs. This relationship must be established to realize the overall sense out of what is said. In all 
languages, discourse markers are studied for their contribution to making any messages in Steve Jobs' speech be successfully conveyed since they can demonstrate connectivity ("act sequence").

The interpretation of how DMs in Steve Jobs' speech function in the case of the structural and interactional aspects and realizing their use in different contexts action is in line with the findings of previous studies (Makoshi, 2014; Ali-Mahadin, 2016; Mohammadi, 2018). For example, in a speech, DMs help to make a text or a speech cohesive and coherent and build social context between the speaker and the hearers. For the text to be clearly understood by the audience, it is necessary to create a harmonious relationship through DMs.

The existence of DMs in the text becomes a means of adding information, managing communication, indicating causal relationships, time markers, and response markers. DMs' role is how expression through language shows having the characteristics of specific grammatical patterns and lexicalization demonstrate a restructuring cognition (Sidnell \& Enfield, 2012). Such contribution is similar to other expressions like those lexical expressions that functioned to maintain social relations among the parties involved in a speech event (Kendrick, 2015; Juanda \& Azis, 2018). Kendric (2015) discussed conversational repairs that play a role in building a social relationship between a speaker-hearer (Kendric, 2015). The conversational repairs are placed to have their practical function from a pragmatic viewpoint. For example, in the Indonesian context involving two ethnic groups, i.e., Bugis and Betawi, turn-taking in conversational interactions show the social status of the speakers between the more senior and younger speakers, the change of topic, and transition markers in turn-taking using the words used for greeting and exclamative expressions (Juanda \& Azis, 2018)). The use of lexical expressions having similar characteristics of DMs in Job's speech does not merely function as coherence but also establishes an "interaction" when Jobs utter his statement and the audiences pay careful attention to understand the implied message behind all statements.

\section{Discourse Markers and the Social Aspect in Steve Jobs' Speech}

The social context of DMS in speech is the establishment of a relationship between the speaker and the audience ("participant") and the presence of interactive and communicative ambiance in the speech delivery ("setting and scene"). The content of speech ("act sequence" and "ends") must be coherent so that the speaker can inspire according to all the elements in Del Hyme's speaking model. The previous studies on DMs in speeches have interpreted its characteristics focusing on the function of DM, particularly in speeches (Marbun, 2017; Bantawig, 2019). These previous studies do not explore the social context that involves broader aspects, which are not only in the speech texts but also in how DMs help establish social interaction among the involved parties. This study offers an analysis model of DMs in the text and looks at its function by describing the 'speaking' factors that speakers may consider. The use of Del Hymes in speaking reinforces Fraser's opinion that DMs must also be seen as a unit of analysis from a pragmatic perspective. This study takes a sociolinguistic theory to describe the function of each marker comprehensively.

\section{Markers of Connective Datum 1 \\ "And"}

"I had no idea what I wanted to do with my life and no idea how college was going to help me figure it out"

DM "and" in the complex sentence (datum 1) is found in the beginning part of Steve Jobs' speech. The two independent clauses need a marker of connective "and" to connect the first expression saying that "Jobs did not know what he wanted in his life" with the second expression about "how college would show him his life goal." The DM "and" marks the connective function, which plays a role as a discourse coordinator. This function can be seen from how the marker of connective "and" is positioned in the middle of two different ideas linked together. The two ideas can just be gathered by using "and." The expression like "I had no idea what I wanted to do with my life" (1) and "no idea how college was going to help me figure it out" (2) can be 
interpreted as having the function to describe Steve Jobs's thought. The connective marker "and" in the statement has functioned as the discourse coordinator and continues the speaker's idea. The speech gains its function to show the audience the confusion in his early life. It is the starting point of what he calls "connecting the dots."

\section{Datum 2 \\ "But" \\ "I had been rejected, but I was still in love."}

In his speech, datum 2 is a very significant statement found in the second story of Steve Jobs. It is called "love and lost." The marker of connective "but" is used to describe two contradictory events. The marker "but" here functions as the connective marker, which marks the contrasting situation. It is seen clearly from Steve Jobs' statement. When he chooses to use the marker "but," Jobs emphasizes a powerful thought. He combines the contrasting ideas saying, "although he was rejected, he was still in love."

Concerning 'speaking model' to show the social situation in the speech, the dominant aspects of 'speaking model' related to the use of DMs "but" is "participant" (the involved parties), "end" (the objective), and "key" (the spirit of interaction). In Jobs' story, he had been rejected and fired at the age of 30 . However, he still loved what he had started when he was 20 , and ten years later, he succeeded in running a company from only two persons into 4000 employees with the creation of Macintosh, the finest creation of Apple that had just been released.

\section{Datum 3}

"Or"

"Because almost everything - all external expectations, all pride, all fear of embarrassment or failure - these things just fall away in the face of death, leaving only what is truly important

Datum 3 shows the use of a marker of connective "so" to present the options supporting the complete expression of ideas the speaker wants to share. The statement in datum 3 reflects the application of DMs "so" as a connective marker that marks the speaker's provision of options. In this case, the hearer has not given a choice, but Steve Jobs himself, as the speaker tries to emphasize what is meant by "everything" in his speech. He gives further options to what "everything" means in the statement. It involves all intangible feelings that human beings can deepen in their heart. Jobs further mentions the feelings by using "so" at the end of the choices. The statement in datum 3 is found in the third story of Steve Jobs that is labeled as "death." In part of the speech about "death," Jobs begins with the quotation that inspires him at 17. At that time, he read a quote saying, "If you live each day as if it was your last, someday you'll most certainly be right." This quote led to the awareness of making a total effort in everything he wanted to do.

The spirit of communication in the event can also be found in Jobs' statement. In his wise words, Jobs reminds the participants about death, which The certainty about death is the most significant medium Jobs has ever encountered to assist him in making the big choices in life. Everything in life, including hopes, pride, fear of being embarrassed, or even failure, means nothing in the face of death. The statement leaves only a critical message that people should not lose something in life. Following our heart is the condition that Jobs suggests to the audience, which is actually the "key" of social construction that the speaker wants to construct through his statements, particularly those using the marker of connective, "or."

\section{Markers of Cause and Result}

\section{Datum 4 \\ "Because" \\ "Because I had dropped out and didn't have to take the normal classes, I decided to take a calligraphy class to learn how to do this."}

Datum 4 shows the use of marker of cause \& result "because ."The marker here plays a role as a marker of subordinate idea unit. It is a part of a larger discourse unit that initiates the explanatory unit or reasons. It is clear that "because" shows the cause and result relation to present the reasons and implications of the story told in the speech. The causal relation is clearly shown in Steve Jobs' statement that "he decided to take a calligraphy class." This decision is taken after 
"he had dropped out and didn't have to take the normal classes."

From its social context, the use of the marker "because" contributes to "act sequence" and "reaction related to the content of the speech. In this case, the result was in the form of action. The sequence that refers to the arrangement in the content is expressed through the use of causal relation "because ."What Steve Jobs means in his statement is that he learns a lot from the skills developed in the calligraphy class. From his statement, DM "because" can also help construct the causal relation to make the participants realize the effects of a particular decision.

\section{Datum 5}

\section{"So"}

"I didn't have a dorm room, so I slept on the floor in friends' rooms, I returned Coke bottles for the $5 \phi$ deposits to buy food with, and I would walk the 7 miles across town every Sunday night to get one good meal a week at the Hare Krishna temple."

Datum 5 shows the use of marker of cause and result "so."This marker functions as the complementary marker of the central idea unit. It means that "so" is used to consequence one condition. For example, it sounds pretty dramatic to hear from Steve Jobs that "he didn't have a dorm room." The consequences of this condition are told in detail in the statements that follow the statement, i.e., "sleeping on the floor in friends' rooms," "returning Coke bottles for the $5 \phi$ deposits to buy food with, and "walking the 7 miles across town every Sunday night to get one good meal a week at the Hare Krishna temple."

In line with the use of DM "because" in datum 4, the use of "so" functions to strengthen the effort of involving the participants by presenting the consequences that Steve Jobs mentions to follow the statement about his condition with no dorm room. The marker "so" is used to explain consequences clearly. In its social context, the use of "so" is to emotionally involve the participants in the speech delivered by Steve Jobs as the speaker to make a vivid description. He also gives additional information to describe the condition results mentioned in his previous statement. For example, the statement "I didn't have a dorm room" refers to the condition when Steve Jobs dropped out. His right of the room in the university's dormitory is also gone. Steve Jobs uses the marker "so" as the connector and starts explaining if he sleeps on the floor of his friend's room and tries to work to fulfill his living needs.

\section{Markers of Response Datum 6}

"How can you get fired from a company you started? So as Apple grew, we hired someone who I thought was very talented to run the company with me, and for the first year or so, things went well.

Datum 6 shows the use of the marker of response "well ."Schiffrin (1987) stated that "well" is an exciting marker because it plays a significant role in a sentence. Instead of seeing "well" from the semantic and grammatical point of view, "well" maintains the idealized assumption, which is much related to pragmatic expression. In datum 6, "well" shows the conversational movement from a question uttered by Steve Jobs himself like "How can you get fired from a company you started?. This question is responded directly by Steve Jobs with the statement preceded by "well" that demonstrates the use of "well" as the marker of response. "Well" marks the speaker's self-response to the previous question. This response connects the question and answer that becomes a usual pattern in a speech. The answer supported by "well" sounds like solid reasoning reflecting the effort of Steve Jobs as the speaker to give a different style of giving argument and stories.

Compared to Heritage (2015), well is considered to be used in establishing the social relation because it can respond to the questions they use, shifting the topic and topic closure, and emphasizing the speaker's judgments. From its social context, the use of DM "well" contributes to the attempt of achieving the "ends" of the 'speaking model,' referring to the objective of the speech event, which is to open the alumni's mindset to the life challenges and the commitment to dedicate themselves to the things they love in life. 


\section{Markers of Temporal Adverbial}

\section{Datum 7}

"Now"

"Pixar went on to create the world's first computer-animated feature film, Toy Story, and is now the most successful animation studio in the world."

The use of a temporal marker is fully represented by "now" and "then." In datum 7, "now" and "then" as markers of temporal adverbials have the characteristic of time deictics. DM "now" in datum 7 shows the arrangement of phenomena from the past to the latest condition showing the importance of time sequence to understand significant life changes. Steve Jobs illustrates the development in the company for which he dedicates his life. Marker of temporal adverbial "now" functions to introduce the subtopic in terms of time. The function is realized when Steve Jobs states, "Pixar went on to create the world's first computer-animated feature film." The topic and the additional information connected by "now" is a subtopic to describe the latest achievement that Pixar gets, which is "the most successful animation studio in the world."

The marker "now" in datum 7 is used to describe the continuous progress of Pixar. Reflecting how the 'speaking model' is found in the speech delivery, the use of temporal adverbial markers supports the aspect of "act sequences," "key," and "genre." For example, DM "now" as a time deictic shows the connection when a proposition is thought to be true. The "key" aspect in the speech delivery is how Steve Jobs delivered his speech about his past. The use of "now" shows the function to give a detailed description of the movement from one event to another.

\section{Datum 8 \\ "Then"}

"I dropped out of Reed College after the first 6 months, but then stayed around as a drop-in for another 18 months or so before I really quit."

The marker "then" marks the function to express the following event times. It means that the marker "then" is used to explain the following event as the sequence or the continuation of the event described in the statement. For example, datum 8 employs "then" between two different events. DM "then" connects the proposition "I dropped out of Reed College after the first 6 months" (1) and "stayed around as a drop-in for another 18 months or so before I really quit". (2). Two propositions here are connected with "then" that plays a role to be not merely the time adverbial. Instead, it shows the connection between one event (1) and the next event (2) as the description of the time sequence and its phenomenon.

Similar to datum 7, the use of DM "then" in datum 8 supports the aspect of "act sequences", "key," and "genre." DM "then" is also a time deictic. It connects the events between times, reflecting a factual proposition. Seen from the social context of how a speech is delivered, the "key" aspect of the 'speaking model' in Steve Jobs's speech can be found from the content of the speech, which includes the use of DM "then ."Using time deictics like "now" and "then" also makes the motivational speech flow beautifully and helps the participants understand the content better. They can comprehensively catch the movement from one story to the other presented in the speech.

To sum up, this study relates the use of DMs with the 'speaking model' in showing how a specific type of DM is used to express ideas to represent the intention of the speaker to make the hearers reach the message in the speech. The choice of DM has its pragmatic effect. They establish the social context of why DMs are needed to link two statements, manage the information, and show the correlation of time sequence. When the speaker (Steve Jobs) delivered his speech, he initiated the interaction and the detail on the sequences of events in his life. Language is the individual and social world. The social context of DMs is not explored widely in the previous studies. This study attempts to reveal the social context of why different types of DMs are used to represent the expression. The function of each DM is analyzed to show the construction of their social aspect. The way the speaker connects his ideas from one point to another must be based on his intention to make the audience understand their message. 


\section{CONCLUSION}

Speech is a type of public speaking that encourages the speaker to share their idea obviously both in terms of content and performance. This study was conducted to discuss discourse markers in speech and their functions concerning the social context. The identification of discourse markers was combined with how they can be functioned to construct the social situation. The findings showed that four discourse markers were used in Steve Jobs' Stanford Commencement Address. They included connective markers, cause \& result markers, temporal adverb markers, and response markers.

In order to connect all statements coherently, discourse markers were utilized in the speech to connect Steve Jobs' three stories, i.e., connecting the dots, love, and loss, and death that was prominently told the audience about the significance of particular events to the other events happening in one's life. The implication of using all discourse markers in the speech is to gain coherent message delivery by considering the "setting and scene," "participants," "ends," "act sequences," "key," "instrumentalities," "norms of interaction," "genre" that is shortened in the acronym of 'speaking.' In this way, building a relationship between the speakers and the audience of the speech event is a crucial task of a speaker. It may be gained not only through good performance on the stage but also the content, i.e., the expression of ideas utilizing the language features to connect, contradict, and show consequences.

\section{REFERENCES}

Abdullah, I. F. S. (2018). Usage of Cohesive Devices By Esl Speakers To Achieve Coherence in Their Speech (Working Paper) Kuala Lumpur: Kulliyyah of Languages and Management International Islamic University, Malaysia

Agbontaen, K. (2019). A-Z Mastering the Art of Public Speaking. Lagos State Nigeria: Exceller Books.

Al-khazraji, A. (2019). Analysis of discourse markers in essay writing in ESL classroom. International Journal of Instruction, 12(2), 559-572. https://doi.org/10.29333/iji.2019.12235a

Ali, E. A. M., \& Mahadin, R. S. (2016). The Use of Discourse Markers in Written Discourse by Students of English. International Journal of Humanities and Social Science, 6(3), 45-56.

Banguis-Bantawig, R. (2019). The role of discourse markers in the speeches of selected Asian Presidents. Heliyon, 5(3), e01298. https://doi.org/10.1016/j.heliyon.2019.e01298

Belicová, J. (2011). Japanese Discourse Markers: An Analysis of Native and Non-native Japanese Discourse.

Collins, P. (2012). The Art of Speeches and Presentations. United Kingdom: John Wiley \& Sons.

Fathima, I., \& Abdullah, S. (2018). Usage of Cohesive Devices By Esl Speakers To Achieve Coherence in Their Speech, 121.

Fraser, B. (2010). An Account of Discourse Markers. International Review of Pragmatics, 1(2), 293320. https://doi.org/10.1163/187730909x12538045489818

Heritage, J. (2015). Well-prefaced turns in English conversation: A conversation analytic $\begin{array}{lllll}\text { perspective. Journal of } & \text { Pragmatics, }\end{array}$ https://doi.org/10.1016/j.pragma.2015.08.008 
Hymes, D. (1974). Foundations in Sociolinguistics An Ethnographic Approach. Philadelphia: University of Pennsylvania.

Johnstone, B., \& Marcellino, W. M. (2010). Dell Hymes and the ethnography of communication. The SAGE Handbook of Sociolinguistics, (May), 57-66. https://doi.org/10.4135/9781446200957.n4

Juanda, \& Azis. (2018). Penanda 'Turn-Taking Etnis Bugis dan Betawi dalam Percakapan Bahasa Indonesia. KEMBARA Journal of Scientific Language Literature and Teaching, 4, 179-191.

Kendrick, K. H. (2015). Other-initiated repair in English. Open Linguistics, 1(1), 164-190. https://doi.org/10.2478/opli-2014-0009

Kusumayati, L. D. (2016). The Use of Discourse Markers in Written Discourse by Students of English. International Journal of Humanities and Social Science, 6(3), 45-56.

Makoshi, M. A. Al. (2014). Manal A. Al Makoshi !, (June).

Marbun, F. . (2017). An Analysis of Discourse Markers in Donald Trump's Speeches. Universitas Sumatera Utara.

Maschler, Y., \& Schiffrin, D. (2015). Discourse Markers, Language, Meaning, and Context. In Tannen, D Hamilton H. E., \& Schiffrin, D (Eds.) The Handbook of Discourse Analysis. New Jersey: John Wiley \& Sons Inc

Mohammadi, A. N. (2020). Discourse markers in colloquial and formal Persian : a corpus-based discourse analysis approach [Dissertation, University of Florida]

Rafiah, S. (2018). Understanding CDA: Histories, Remembering, And Futures. Script Journal: Journal of Linguistic and English Teaching, 3(2), 175. https://doi.org/10.24903/sj.v3i2.170

Rahayu, M., \& Rakhmawati, D. E. N. (2020). "Narrative of the Self ": the Discourse of Daily Life in the Essays By Participants of Literacy Workshop. LiNGUA: Jurnal Ilmu Bahasa Dan Sastra, 15(1), 55-64. https://doi.org/10.18860/ling.v15i1.9476

Ray, M., \& Biswas, C. (2011). A study on Ethnography of communication : A discourse analysis with Hymes ' speaking model.' Journal of Education and Practice, 2(6), 33-41.

Rezanova, Z. I., \& Kogut, S. V. (2015). Types of Discourse Markers: Their Ethnocultural Diversity in Scientific Text. Procedia - Social and Behavioral Sciences, 215(June), 266-272. https://doi.org/10.1016/j.sbspro.2015.11.633

Schiffrin, D. (1987). Discourse Markers. Cambridge: Cambridge University Press.

Sharndama, E. C., \& Yakubu, S (2013). An Analysis of Discourse Markers in Academic Report Writing: Pedagogical Implications, International Journal of Academic Research and Reflection 1(3), 15-24.

Sidnell, J., \& Enfield, N. J. (2012). Language diversity and social action a third locus of linguistic relativity. Current Anthropology, 53(3), 302-333. https://doi.org/10.1086/665697

Stewart, J. ., \& Fulop, D. (2019). Mastering The Art of Oral Presentations Winning Orals, Speeches, and Stand-Up Presentations. New Jersey: John Wiley \& Sons. 
Umezinwa, J. (2019). Analysis of a Selected Bargain Discourse Using Dell Hymes ', (June). https://doi.org/10.13140/RG.2.2.21516.16004

Yeganeh, M. T., \& Ghoreyshi, S. M. (2015). Exploring Gender Differences in the use of Discourse Markers in Iranian Academic Research Articles. Procedia - Social and Behavioral Sciences, 192, 684-689. https://doi.org/10.1016/j.sbspro.2015.06.104

Yuhas, B. (2013). An Analysis of Discourse Markers and Discourse Labels as Cohesive Devices in ESL Student Writing. Colorado State University.

Zand-vakili, E., Fard, A., \& Farhad, K. (2012). The Analysis of Speech Events and Hymes ' SPEAKING Factors in the Comedy Television Series : "FRIENDS ," 2, 27-44.

Online sources

https://www.youtube.com/watch?v=UF8uR6Z6KLc.

https://news.stanford.edu/2005/06/14/jobs-061505/. 